\title{
Analisis Pengendalian Persediaan Bahan Baku Menggunakan Metode Min-Max (Studi Kasus PT.Djitoe Indonesia Tobacco)
}

\author{
Ade Putri Kinanthi $^{* 1)}$, Durkes Herlina ${ }^{2)}$, dan Finda Arwi Mahardika ${ }^{3)}$ \\ ${ }^{1,2,3}$ Program Studi Teknik Industri, Fakultas Teknik, Universitas Sebelas Maret \\ Teknik, Universitas Sebelas Maret \\ J1. Ir. Sutami 36A Surakarta 57126 \\ Telp. 0271-6322110
}

\begin{abstract}
Inventories of raw materials are the company's current assets used for production activities at the company. Companies need to do the inventory control because it affects the smooth production process. A shortage can lead to disruption of the production process. While excess inventory can lead to waste because companies need to spend more capital for inventory costs. The purpose of this study to determine whether the PT. Djitoe Indonesia Tobacco has made raw material inventory control appropriately. Raw material inventory control methods used in this study are a min-max stock. This method determines the amount of safety stock, minimum stock, maximum stock and order quantity. After doing research, PT. Djitoe Indonesia Tobacco excess raw material inventory. Total inventories are controlled using the minmax stock produces more efficient results when compared to the amount of the final inventory of the company. With min-max method the company is able to economize IDR 700,000 for each period.
\end{abstract}

Keywords: Inventory Control, Min-max Method, Raw Materials

\section{Pendahuluan}

Persediaan berperan penting bagi perusahaan. Persediaan bahan baku merupakan elemen terpenting dalam produksi yang dilakukan oleh perusahaan untuk menghasilkan produk (Prima, 2014). Persediaan dapat diartikan sebagai barang-barang yang disimpan untuk digunakan atau dijual pada masa atau periode yang akan datang (Ristono, 2009:1). Persediaan adalah suatu aktiva yang meliputi barang-barang milik perusahaan dengan maksud untuk dijual dalam suatu periode usaha tertentu atau persediaan barang-barang yang masih dalam pengerjaan atau proses produksi ataupun persediaan bahan baku yang menunggu penggunaannya dalam suatu proses produksi (Alexandri, 2009:135). Persediaan merupakan salah satu masalah yang perlu diperhatikan dalam kaitannya dengan kegiatan proses produksi, biaya serta distribusi barangbarang, baik itu bahan baku, barang dalam proses atau barang setengah jadi, ataupun barang jadi (Fadlillah dkk., 2008). Bahan baku yang dibutuhkan hendaknya cukup tersedia sehingga dapat menjamin kelancaran produksi. Akan tetapi hendaknya kuantitas persediaan itu jangan terlalu besar agar modal yang tertanam dalam persediaan dan biaya-biaya yang ditimbulkannya tidak terlalu besar dan jangan pula terlalu kecil karena dapat memperlambat proses produksi (Ruauw, 2011).

PT. Djitoe Indonesia Tobacco merupakan perusahaan yang bergerak dibidang industri, yang kegiatan utamanya adalah memproduksi rokok. Bahan baku yang digunakan dalam proses produksi ini adalah tembakau, cengkeh dan saos. Bahan-bahan tersebut harus selalu tersedia untuk kelancaran proses produksi. Oleh sebab itu perlu dilaksanakan perencanaan dan pengendalian bahan baku. Pengawasan persediaan merupakan masalah yang sangat penting, karena jumlah persediaan akan menentukan atau mempengaruhi kelancaran proses produksi serta keefektifan dan efisiensi perusahaan tersebut. Jumlah atau tingkat persediaan yang

\footnotetext{
*Correspondance : adeputrikinanthi@gmail.com
} 
dibutuhkan oleh perusahaan berbeda-beda untuk setiap perusahaan, pabrik, tergantung dari volume produksinya, jenis pabrik dan prosesnya (Assauri, 1998:177). Pertimbangan akan pentingnya ketersediaan bahan baku sesuai kuantitas produksinya ini menyebabkan bahan baku tersebut harus selalu siap sedia sebanyak kuantitasnya tiap periode produksi agar persediaan bahan baku ini selalu terpenuhi dengan biaya minimum (Prima, 2014).

Maka penelitian ini bertujuan untuk mengetahui PT. Djitoe Indonesia Tobacco telah melakukan pengendalian persediaan bahan baku dengan tepat. Sebelum melakukan pengendalian dicari dulu apakah penyebab dari penumpukan bahan khususnya tembakau dengan menggunakan fishbone diagram. Metode pengendalian persediaan bahan baku yang digunakan pada penelitian ini adalah metode min-max stock. Metode min-max stock adalah metode pengendalian bahan baku yang didasarkan atas asumsi bahwa persediaan bahan baku berada pada dua tingkat, yaitu tingkat maksimum dan tingkat minimum. Jika tingkat maksimum dan tingkat minimum sudah ditetapkan, maka pada saat persediaan sampai ke tingkat minimum pemesanan bahan baku harus dilakukan untuk menempatkan persediaan pada tingkat maksimum. Hal ini untuk menghindari jumlah persediaan yang terlalu besar atau terlalu kecil. Penerapan metode min-max dilakukan sehinggagudang dapat mengetahui berapa stok minimum yang harus ada di gudang untuk memenuhi kapasitas kuantitas produksi serta berapa stok maksimum bahan baku di gudang agar tidak terjadi pemborosan biaya persediaan (Fithri dan Sindikia, 2013). Dengan begitu perusahaan akan terhindar dari berlebihnya persediaan yang mengakibatkan pemborosan dan persediaan bahan baku yang terlalu kecil dapat menghambat kelancaran proses produksi.

\section{Landasan Teori}

Banyak sekali metode yang dapat digunakan untuk mengetahui penyebab dari suatu permasalahan yang ada. Salah satu metodenya adalah menggunakan analisis sebab akibat dengan fishbone diagram. Fishbone diagram (diagram tulang ikan) sering disebut juga diagram Ishikawa atau cause-and-effect diagram (diagram sebab-akibat). Fishbone diagram adalah alat untuk mengidentifikasi berbagai sebab potensial dari satu efek atau masalah, dan menganalisis masalah tersebut melalui sesi brainstorming. Fungsi dasarnya adalah untuk mengidentifikasi dan mengorganisasi penyebab-penyebab yang mungkin timbul dari suatu efek spesifik dan kemudian memisahkan akar penyebabnya (Yamit, 2010). Masalah akan dipecah menjadi sejumlah kategori yang berkaitan, mencakup manusia, material, mesin, dan sebagainya. Setiap kategori mempunyai sebab-sebab yang perlu diuraikan melalui sesi brainstorming. Kategori sebab utama mengorganisasikan sebab sedemikian rupa sehingga masuk akal dengan situasi. Kategori-kategori tersebut adalah man, method, money, material, machine, dan environment.

Dalam suatu perusahaan baik itu perusahaan perdagangan maupun perusahaan manufaktur pasti selalu mengandalkan persediaan. Persediaan sebagai kekayaan perusahaan, memiliki peranan penting dalam operasi bisnis (Sylvia, 2013). Dalam perusahaan manufaktur, persediaan dapat terdiri dari persediaan bahan baku, bahan pembantu, barang dalam proses, barang jadi, dan persediaan suku cadang. Menurut Syakur (2009;125), persediaan meliputi segala macam barang yang menjadi objek pokok aktivitas perusahaan yang tersedia untuk di olah dalam proses produksi atau di jual. Prawirosentono (2001) menyatakan persediaan adalah kekayaan lancar yang terdapat dalam perusahaan dalam bentuk persediaan bahan mentah/bahan baku (raw material), barang setengah jadi (work in process), dan barang jadi (finished goods).

Dalam perusahaan manufaktur, apabila persediaan bahan baku kurang atau bahkan habis (out of stock) maka dapat menghambat proses produksi dan bahkan mengakibatkan terhentinya proses produksi. Sebaliknya jika persediaan terlalu banyak (over stock) maka dapat menimbulkan pemborosan. Investasi yang terlalu besar pada persediaan akan berbanding lurus terhadap biaya penyimpanan, yaitu biaya yang dikeluarkan sehubungan dengan kegiatan 
penyimpanan bahan baku yang dibeli (Puspika dan Anita, 2013). Oleh karena itu perlu dilakukan pengendalian persediaan. Pengendalian persediaan adalah aktivitas-aktivitas dan teknik-teknik penjagaan stock barang-barang pada tingkat tertentu, baik berupa bahan baku, barang dalam proses dan produk jadi (Smith dalam Hadiguna dan Machfud, 2008).

Salah satu cara untuk mengendalikan persediaan adalah dengan cara menentukan stok minimal dan stok maksimal dalam gudang suatu perusahaan. Metode min-max stock adalah metode pengendalian persediaan stock pengaman yang harus ada, kebijakan persediaan minimum, dan persediaan maksimum. Pengendalian persediaan menggunakan metode min-max stock meliputi beberapa tahapan yaitu:

1. Menentukan Persediaan Pengaman (Safety Stock). Safety stock atau persediaan pengaman adalah persediaan ekstra yang perlu ditambah untuk menjaga sewaktu-waktu ada tambahan kebutuhan atau keterlambatan kedatangan barang.

2. Menentukan Persediaan Minimum (Minimum Inventory). Minimum Stock adalah saat atau titik dimana pemesanan kembali harus diadakan sehingga kedatangan atau penerimaan bahan tepat pada waktunya dimana jumlah persediaan sama dengan safety stock. Dalam metode persediaan yang lain, minimum stock biasanya disebut dengan Re Order Point.

3. Menentukan Persediaan Maksimum (Maximum Inventory). Maximum Stock adalah jumlah maksimum yang diperbolehkan untuk disimpan dalam persediaan.

\section{Metode Penelitian}

Penelitian dilakukan secara bertahap dan sistematis secara lengkap dapat dijelaskan sebagai berikut :

\section{Penelitian Pendahuluan}

Tahap pertama adalah penelitian pendahuluan dilakukan untuk mengetahui lebih detail tentang informasi-informasi yang diperlukan dalam penelitian. Berdasarkan informasi tersebut maka didapat tahap penyelesaian masalah yang ada, sehingga pembahasan dalam penelitian ini menjadi terarah. Data yang akan digunakan dalam riset haruslah data yang akurat karena data yang tidak akurat akan menghasilkan informasi yang salah.

\section{Pengumpulan Data}

Tahap kedua yang dilakukan adalah mencari akar permasalahan inventory pada perusahaan dengan menggunakan analisis sebab akibat fishbone diagram. Setelah ditemukan penyebab permasalahan inventory perusahaan, dilakukan pengendalian persediaan dengan menggunakan metode min-max stock. Data yang dikumpulkan berupa data pembelian dan pemakaian bahan baku pada perusahaan. kemudian dilakukan perhitungan persediaan pengaman (safety stock).

\section{Pengolahan Data}

Tahap ketiga adalah pengolahan data berisi mengenai pengolahan data-data yang telah diperoleh dari hasil pengumpulan data untuk mendapatkan tujuan dari penelitian ini. Perhitungan persediaan pengaman ini dilakukan guna menjadi input dalam perhitungan minimum inventory dan maximum inventory. Penentuan safety stock dilakukan dengan menggunakan rumus sebagai berikut:

$$
\begin{aligned}
\text { Safety Stock } & =(\text { Pemakaian Maksimum }-\mathrm{T}) \times \frac{C}{30} \\
& \text { Keterangan: } \\
\mathrm{T} & =\text { Pemakaian barang rata-rata per periode } \\
\mathrm{C} & =\text { Lead Time }
\end{aligned}
$$

Tahap selanjutnya adalah menentukan persediaan minimum dan persediaan maksimum pada inventory. Penentuan minimum inventory dilakukan dengan menggunakan rumus sebagai berikut:

Minimum Inventory $=(\mathrm{T} \times \mathrm{C})+\mathrm{R}$ 
Keterangan:

$\mathrm{T}=$ Pemakaian barang rata-rata per periode

$\mathrm{C}=$ Lead Time

$\mathrm{R}=$ Safety Stock berikut:

Maximum Inventory $=\frac{2(\mathrm{~T} \times \mathrm{C})}{30}$

Keterangan:

$\mathrm{T}=$ Pemakaian barang rata-rata per periode

$\mathrm{C}=$ Lead Time

\section{Hasil dan Pembahasan}

Tahap keempat adalah menganalisa hasil dari pengolahan data.

\section{Kesimpulan dan Saran}

Berisikan kesimpulan dari hasil penelitian yang dilakukan.

\section{Hasil dan Pembahasan}

Sebelum melakukan perhitungan menggunakan metode min-max, dilakukan analisis pencarian akar masalah menggunakan fishbone diagram. Adapun hasil fishbone diagram dari penelitian yang dilakukan adalah sebagai berikut :

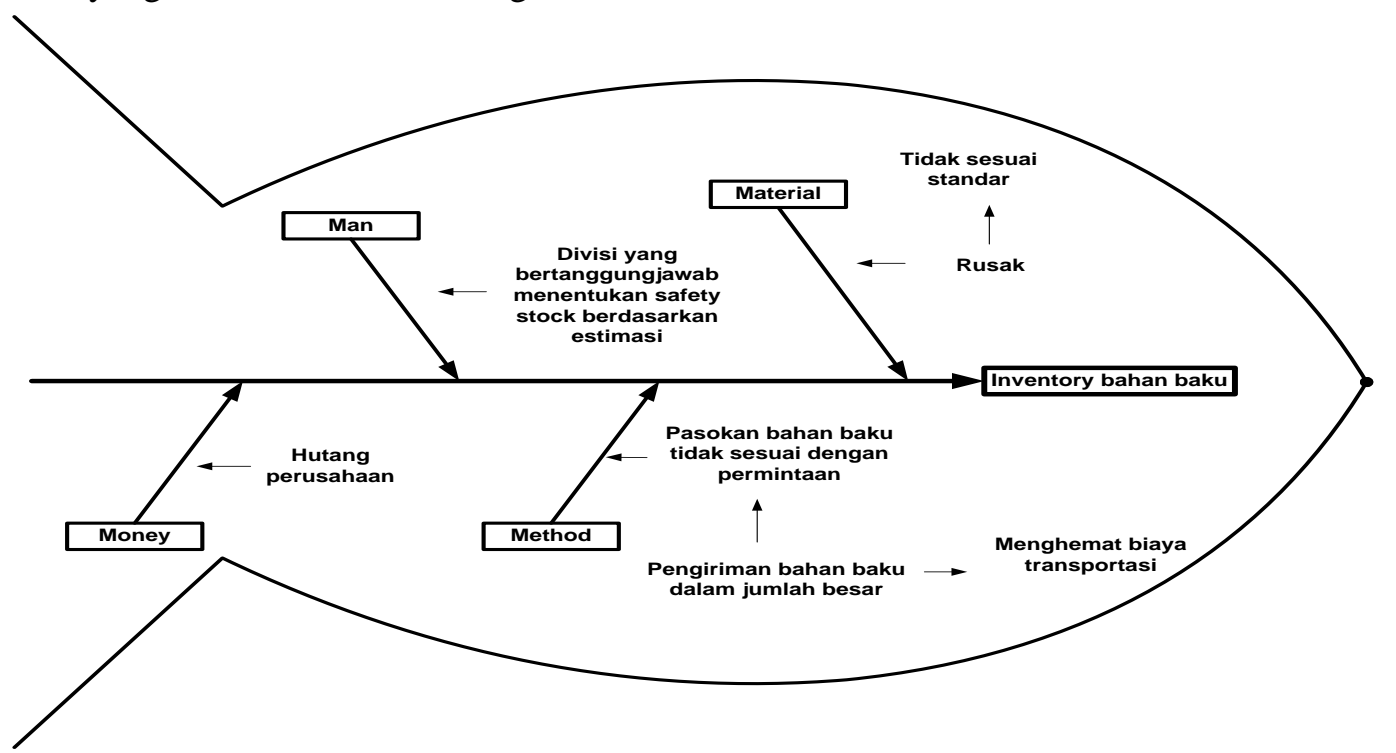

Gambar 1. Fishbone Diagram

Dari fishbone diagram dapat diketahui bahwa perusahaan mempunyai hutang dagang dari pemesanan tembakau yang dilakukan, selain itu material yang rusak dan menumpuk digudang menyebabkan gudang selalu penuh. Dari segi metode perusahaan belum menerapkan sistem yang tepat, dan dari segi manusia divisi yang bertanggungjawab belum menentukan berapa safety stock yang harus ada diperusahaan.

Dari hasil fishbone diagram diagram tersebut kemudian dilakukan proses pengendalian persediaan menggunakan metode min-max stock. Metode ini adalah metode pengendalian inventory yang berusaha menjawab segala permasalahan inventory meliputi stock pengaman yang harus ada, kebijakan persediaan minimum, dan persediaan maksimum. Dengan melihat laporan stock bahan tembakau yang menunjukan bahwa masih banyak tersisa di gudang, maka 
dengan menggunakan metode ini diharapkan tidak terjadi lagi penumpukan tembakau di gudang, dan dapat ditentukan kebijakan persediaan minimum dan persediaan maksimum yang harus ada digudang.

Perhitungan safety stock

$$
\begin{aligned}
\text { - Safety Stock } & =(79.938-65.508) \times(0,1) \\
& =14.430 \times 0,1 \\
& =1.443 \mathrm{Kg}
\end{aligned}
$$

Menghitung persediaan minimum

- Persediaan minimum $=\frac{(65.508 \times 3)+1443}{30}$

$$
\begin{aligned}
& =6.598,85 \\
& =6.599 \mathrm{Kg}
\end{aligned}
$$

Menghitung persediaan maximum

$$
\begin{aligned}
- \text { Persediaan maximum }= & \frac{2 \times(65.508 \times 3)}{30} \\
& =13.101,5 \\
& =13.102 \mathrm{Kg}
\end{aligned}
$$

Setelah dilakukan perhitungan tersebut terlihat perbandingan jumlah stock dalam gudang sebelum dilakukan pengendalian menggunakan metode min-max stock dan setelah dilakukan perhitungan.

Tabel 1. Perbandingan Jumlah Tembakau Dengan Persediaan Minimum

\begin{tabular}{lrl}
\hline & Jumlah Persediaan $(\mathbf{K g})$ & \multicolumn{1}{c}{ Harga } \\
\hline Sebelum & 1.260 .522 & $\mathrm{Rp} \mathrm{37.602.999.473}$ \\
\hline Sesudah & 6.599 & $\mathrm{Rp} 196.856 .694$ \\
\hline
\end{tabular}

Tabel 2. Perbandingan Jumlah Tembakau Dengan Persediaan Maximum

\begin{tabular}{lrc}
\hline & Jumlah Persediaan $(\mathbf{K g})$ & Harga \\
\hline Sebelum & 1.260 .522 & $\mathrm{Rp} \mathrm{37.602.999.473}$ \\
\hline Sesudah & 13.102 & $\mathrm{Rp} \mathrm{390.849.584}$ \\
\hline
\end{tabular}

Besarnya biaya simpan adalah $20 \%$ dari total biaya listrik gudang dan perawatan dengan biaya tenaga kerja yang menjaga gudang. Dimana total tersebut kemudian dibagi dengan kapasitas maksimum dari gudang yang ada. Gudang tembakau dijaga oleh 2 petugas, biaya perawatan dan listrik gudang yaitu $\mathrm{Rp} 1.800 .000$ dan kapasitas maksimum dari gudang adalah $1.500 .000 \mathrm{~kg}$ tembakau. Adapun perhitungan dari biaya simpan gudang adalah sebagai berikut :

$$
\begin{gathered}
\text { Biaya } \\
\left(\frac{\text { Siaya listrik dan perawatan +biaya tenaga kerja }}{\text { kapasitas max.gudang }}\right) \times 20 \% \\
= \\
\left(\frac{R p 1.800 .000+R p 2.600 .000}{1.500 .000}\right) \times 20 \% \\
\mathrm{Rp}= \\
0,59
\end{gathered}
$$

Dengan data tersebut maka apabila perusahaan melakukan pengendalian stock gudang sejumlah yang telah ditentukan dari perhitungan min-max maka besarnya biaya yang dapat dihemat adalah 
Tabel 3. Biaya Simpan Dengan Persediaan Minimum

\begin{tabular}{lrlll}
\hline & Jumlah Persediaan $(\mathbf{K g})$ & Biaya Simpan & \multicolumn{1}{c}{ Total } \\
\hline Sebelum & 1.260 .522 & $\mathrm{Rp} 0,59$ & $\mathrm{Rp}$ & 743.708 \\
\hline Sesudah & 6.599 & $\mathrm{Rp} 0,59$ & $\mathrm{Rp}$ & 3.893 \\
\hline
\end{tabular}

Tabel 4. Biaya Simpan Dengan Persediaan Maximum

\begin{tabular}{lrlll}
\hline & Jumlah Persediaan $(\boldsymbol{K g})$ & Biaya Simpan & \multicolumn{1}{c}{ Total } \\
\hline Sebelum & 1.260 .522 & $\mathrm{Rp} 0,59$ & $\mathrm{Rp}$ & 743.708 \\
\hline Sesudah & 13.102 & $\mathrm{Rp} 0,59$ & $\mathrm{Rp}$ & 7.730 \\
\hline
\end{tabular}

Selain menghemat biaya simpan, perusahaan juga dapat mengurangi nilai hutang perusahaan. Karena periode tersebut hutang perusahaan cukup besar untuk melakukan pengadaan tembakau. Selain itu pengurangan biaya dan kapasitas simpan dirasa sangat membantu karena fluktuasi harga tembakau di Indonesia tidak terlalu signifikan sehingga tidak dibutuhkan persediaan dalam jumlah besar untuk menangani hal tersebut.

\section{Simpulan}

PT. Djitoe Indonesia Tobacco merupakan perusahaan yang bergerak dibidang industri, khususnya produksi rokok. Bahan baku yang digunakan dalam proses produksi ini adalah tembakau, cengkeh dan saos. PT. Djitoe Indonesia Tobacco yang tidak pernah kehabisan bahan baku khususnya tembakau, selalu melakukan pemesanan tembakau dengan jumlah yang tidak sedikit dan menumpuk persediaan dengan kapasitas yang berlebih. Dari hasil analisis menggunakan fishbone diagram dapat diketahui bahwa faktor-faktor yang mempengaruhi kelebihan stok yang ada antara lain man, method, money, dan material. Dengan adanya metode pengendalian persediaan maka PT. Djitoe Indonesia Tobacco mampu menghemat biaya sampai Rp 700.000 untuk setiap periodenya.

Untuk penelitian lebih lanjut diharapkan mampu mendapatkan penghematan yang lebih optimal untuk tiap periodenya. Selain itu, diharapkan mampu ditemukan formulasi untuk mendapatkan komposisi persediaan yang optimal dari setiap bahan baku yang dibutuhkan oleh PT. Djitoe Indonesia Tobacco.

\section{Daftar Pustaka}

Agus Ristono. (2009). Manajemen persediaan edisi 1. Yogyakarta : Graha Ilmu

Assauri, Sofyan. (1998). Manajemen Produksi dan Operasi. Edisi Revisi. Jakarta: BPFE UI.

Fadlillah, dkk. (2008). Metode Pengendalian Persediaan Bahan Baku Crude Coconut Oil yang Optimal Pada PT. PSE. Industrial and Systems Engineering Assessment Journal, Vol 9 No. 2 Universitas Bina Nusantara.

Juliana Puspika dan Desi Anita. (2013). Inventory Control dan Perencanaan Persediaan Bahan Baku Produksi Roti pada Pabrik Roti Bobo Pekanbaru. Jurnal Ekonomi Vol 21 No. 3 Universitas Riau.

Moh. Benny Alexandri. (2009). Manajemen Keuangan Bisnis Teori dan Soal. Alfabeta: Bandung

Prima Fithri, Sindikia Annise. (2014). Pengendalian Persediaan Pozzolan Di PT Semen Padang. Jurnal Optimasi Sistem Industri, Vol 13 No. 2 Universitas Andalas, Padang.

Ruauw, Eyeverson. (2011). Pengendalian Persediaan Bahan Baku (Contoh Pengendalian Pada Usaha Grenda Bakery Lianli. Jurnal ASE Vol 7 No. 1 Universitas Sam Ratulangi, Manado.

Sylvia, Marcy. (2013). Pengendalian Persediaan Bahan Baku Menggunakan Metode Min-Max Stock pada PT. Semen Tonasa di Pangkep. Skripsi Jurusan Manajemen Fakultas Ekonomi dan Bisnis Universitas Hasanuddin, Makassar.

Yamit, Zulian.(2010). Manajemen Kualitas Produk dan Jasa. Yogyakarta : Ekonisia. 